\title{
EGFR NM_005228.3:C.2303G>T
}

National Cancer Institute

\section{Source}

National Cancer Institute. EGFR NM 005228.3:C.2303G>T. NCI Thesaurus. Code C125209.

A nucleotide substitution at position 2303 of the coding sequence of the EGFR gene where guanine has been mutated to thymine. 